\title{
Different Technologies and Components of Renewable Energy Sources based Power System: A Review
}

\author{
Rajesh Kumar \\ M.Tech Scholar, Electrical Engineering Department \\ RPIIT, Karnal, India
}

\author{
Satish Kumar \\ Professor, Electrical engineering Department \\ RPIIT, Karnal, India
}

\section{ABSTRACT}

Variability and intermittency are some of the main features that characterize renewable energy sources. Intermittency usually includes both predictable and unpredictable variations. The many drawbacks of intermittency of renewable sources can be overcome by considering some special design considerations. Integrating more than one renewable energy source and including backup sources and storage systems are among the few measures to overcome these drawbacks. These additional design considerations usually increase the overall cost of the renewable system. Furthermore, the presence of more than one energy supply/storage system requires the control of energy flow among the various sources. Therefore, optimizing the size of the components and adopting an energy management strategy are essential to decreasing the cost of the system and limiting its negative effects. The energy management strategy is commonly integrated with optimization to ensure the continuity of load supply and to decrease the cost of energy production. Therefore, energy management is a term that collects all the systematic procedures to control and minimize the quantity and the cost of energy used to provide a certain application with its requirements. The energy management strategy usually depends on the type of energy system and its components. Various approaches and techniques have been used to develop a successful energy management strategy. In this paper, a comprehensive review of the different combinations and approaches proposed and used by authors of many papers are conducted. These approaches include both the standalone hybrid renewable energy systems and the grid-connected hybrid renewable systems. The selected papers in this review cover the various configurations of the hybrid renewable energy systems for electric power generation only.
KEYWORDS: Standalone hybrid system, Grid connected hybrid system, fuel cell, solar cell, wind turbine.

\section{INTRODUCTION}

The past few decades have shown an accelerated global effort in the development of renewable energy sources and the associated technologies that serve them as energy is now recognized as a strategic sector. Governments all over the world have adopted new regulations and policies encouraging the employment of renewable energy technologies. These efforts include promoting renewable energy technologies, improving the efficiency of energy use, and establishing energy conservation plans alongside their related legislative actions [1], [2], [3], [4] and [5]. The development has covered various renewable energy sources, backup sources, and storage systems. Combining them with conventional sources to supply isolated loads or mini-grids located far from the main grid is the solution to ensure the continuity of supply because of the intermittent nature of renewable sources. An energy system that uses more than one energy source is called a hybrid system. If renewable energy sources are chosen appropriately for each geological location, the need for fossil fuel will be considerably reduced, thus leading to an increase in power supply sustainability, especially in countries that depend on external sources to supply different types of loads [6], [7], [8] and [9]. Integrating conventional sources with renewable sources can improve the reliability of the electrical power system, especially in difficult environmental conditions, and also reduce the limitations of renewable sources and open markets for investment that otherwise may not exist [10] and [11].

Matching renewable generation intermittency to demand in an electricity supply system was the reintroduction of the Energy Storage System (ESS) technologies in the power systems. Besides storing and smoothing renewable power, there are numerous 


\section{www.ijtsrd.com}

advantages related to the advent of ESSs in the power systems. ESSs can increase power system operation and planning resiliency and efficiency by means of many applications including:

- Energy time shift

- Supply capacity

- Load following

- Area regulation

- Fast regulation

- Supply spinning reserve

- Voltage support

- Transmission congestion relief

- Transmission and Distribution upgrade deferral

- Power quality

- Renewable energy time shift

- Renewable capacity firming

- Renewable energy smoothing

- Service reliability

- Black-start

Despite numerous research efforts in order to improve ESS capabilities over the past decade [12], a perfect ESS technology that copes the drawbacks in terms of all aspects is not to be expected to develop in the near future. On the other hand, particular ESS applications require a combination of energy and power rating, charge and discharge time, life cycle, and other specifications that cannot be met by a single ESS technology. In order to increase the range of advantages that a single ESS technology can offer and at the same time enhance its capabilities without fundamental development of the storage mechanism and only via complementary use of the existing ESS technologies, more than one ESS technologies can be hybridized [13].

\section{ESS in Hybrid Power System}

The role of ESSs is very important in growing renewable energy systems (RESs) penetration level, controlling the frequency, upgrading the transmission line capability, mitigating the voltage fluctuations and improving the power quality and reliability [14]. ESS acts as a regulator that manages the fluctuations of electricity from RERs as RERs are not predictable. These fluctuations have limited the penetration of RERs in the DGPs. A huge and reliable storage capacity can provides an opportunity to highly exploit intermittent nature renewable resources in collaboration with power grids to meet the requirements for a more sustainable future [15].With the use of ESSs the transition from conventional to cleaner and greener energy resources can be employed to the modern power system. However, due to high capital cost and lack of experience are some reasons that prevent the commercialization of ESSs technology. Yet it is expected that ESSs will rise in near future due to various reasons as follows:

- There is need to meet short-term, random fluctuations in demand and so avoid the need for frequency regulation by the main plant. It can also provide 'ride through' for momentary power outages, reduce harmonic distortions, and eliminate voltage sags and surges.

- ESSs are also required to eliminate the need for part-loaded main plant which is held in readiness to meet sudden and unpredicted demands, as well as power emergencies which arise from the failure of generating units and/or transmission lines.

- ESSs are needed to accommodate the minute-hour peaks in the daily demand curve.

- ESSs are required to store the surplus electricity generated overnight (i.e. during off-peak hours) to meet increased demand during the day.

- Also the green house gas effect can be reduced by using green energy sources and this can be helped by ESSs.

The electrical energy can be saved only by converting it to others form of energies like mechanical energy, chemical energy, electro-chemical energy, thermal energy, elctro-magnectic energy etc [16]. In Figure. 2 the different methods of energy storages according to their form of energy are classified.

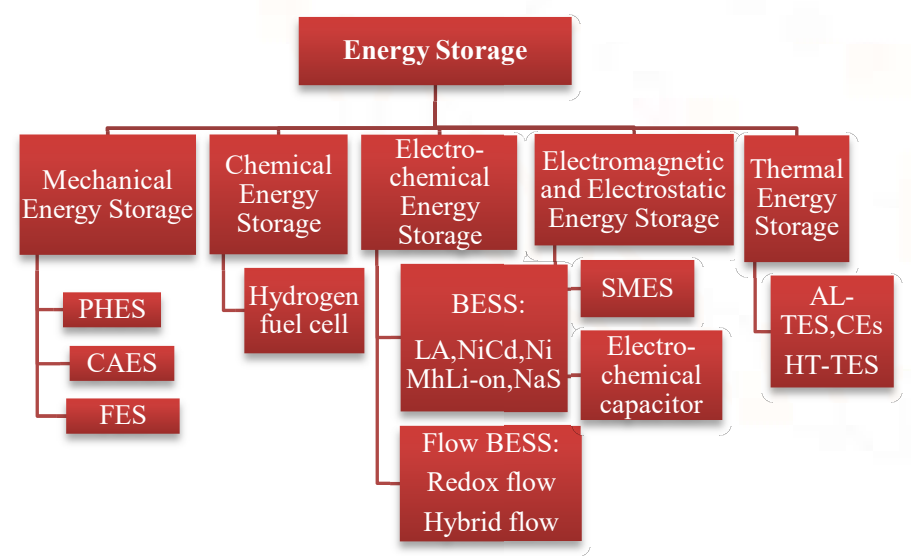

Fig. 1 Different ESS in Hybrid power system 


\section{Renewable and sustainable development}

At present, more mature and reliable renewable energies are on the rise and competitive to the conventional energy sources. Shore wind, solar, concentrated solar, geothermal, marine energy, and bio-energy are on track; and in some circumstances, they have overcome the economic constraints. The share of renewable energy sources in the global final energy consumption is increasing.

In 2012, renewable energy provided an estimated 19\% of the global final energy consumption, and it increased to $23.7 \%$ in 2014 . The year 2015 has been an extraordinary year for renewable energy, with the largest global capacity additions seen to date. It has been observed that, among various renewable energy sources, the hydropower share is on the top at $16.6 \%$ of the total $22.7 \%$, while the wind, biopower, and solar power shares are $3.7 \%, 2.0 \%$ and $1.2 \%$, respectively. Other renewable energy sources, concentrated solar photovoltaic, marine, geothermal, and others contribute to only $0.4 \%$.

It has been reported in the global status report (GSR) on renewable in 2016 that the most significant growth in sustainable energy occurred in the power sector with the global capacity exceeding $1560 \mathrm{GW}$ (including small hydropower). The investment on the renewable energy resources has also increased significantly over the last ten years. A summary of the investment over last 12 years is shown in Fig. 2. A total of 40billion USD was invested by global investors in the field of renewable energies in 2004. The investment kept on increasing and reached 279billion USD in 2011; but after 2011, it began decreasing. This decline is due to the drastic reduction in technology costs especially for solar PV, which saw a record of new installations in despite a reduction in dollar investment.

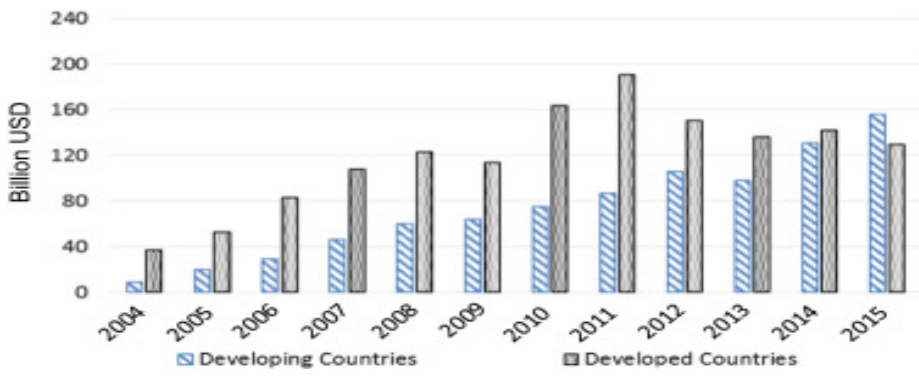

Fig. 2 Developed and developing countries investment in renewable energies
A considerable shift in the global perceptions of renewable energy has been observed since 2004. The rapid progress in the technological field of several renewable energy technologies in the last decade has shown that their potential is achievable. Renewable energies have advanced closer to realizing that potential within the last decade and many technologies are at par with conventional energy generation technologies. According to GSR-2016, in terms of the total installed renewable power capacity, China, the United States, Brazil, Canada and Germany remain the top countries. China, the United States, and Germany were the also the top countries for non-hydrogen capacity and are followed by Spain, Italy, and India. From an investment point of view, Mauritania, Honduras, Uruguay, Morocco, and Jamaica were among the top countries for investment in new renewable power and fuels relative to the annual GDP.

\section{A. Energy management strategies in standalone hybrid renewable energy systems}

This section reviews the various energy management approaches used in standalone hybrid renewable energy systems. Some of the reviewed studies in this section used linear programming to implement energy management, and others used intelligent techniques. The following two sections present the reviewed studies that used these two approaches to implement energy management for standalone hybrid systems, respectively.

Dursun and Kilic [27] examined the performance of three developed power management strategies for a standalone hybrid power system consisting of $\mathrm{PV} /$ wind/PEMFC, where the PV and wind source serve as the main supply and the PEMFC serves as a backup source. The strategies aimed to increase the operation of the fuel cell (FC) membrane and to ensure the continuous flow of energy in the hybrid system. In this study, the authors evaluated battery efficiency using the developed power management strategies in a Matlab/Simulink control algorithm in consideration of the battery state-of-charge (SOC) and the excess power from the main source (wind and PV) after meeting the load demand. In the first strategy, whenever the battery SOC is within the specified limit and excess power from the main source is available, the battery discharges and the excess power is made to run the electrolyzer. However, when the battery SOC is less than the minimum and no excess power from the main source is available, the FC operates to supply the load and charge the battery. In the second 


\section{www.ijtsrd.com}

strategy, the developed algorithm indicates that when the battery's SOC is within the specified limit and no excess power from the main source is available, the FC is disabled and the battery discharges; however, when the battery SOC is less, the battery charges. The third strategy specifies that when the battery SOC is within the specified limit and excess power is available from the main source, the excess power is made to operate the electrolyzer and charge the battery. However, when the battery's SOC decreases below the limit or when excess power from the main source is available, the FC operates to supply the load and charge the battery.

Out of the three strategies, the third developed algorithm was found to produce the best results in terms of battery efficiency with an efficiency rating of about $85 \%$.

\section{B. Energy management based on intelligent techniques standalone applications}

In recent times, many studies have been conducted on energy management of hybrid systems using intelligent techniques, such as genetic algorithm (GA), differential evolution (DE), neural network, fuzzy logic, and neuro-fuzzy, among others. This subsection reviews some of these studies. A more detailed review on the fuzzy logic application in energy management systems will be presented in a later section.

Abedi et al. [17] presented a novel method for determining the optimum power management strategy of hybrid power systems consisting of various sources of energy and storage systems. In this research, the dispatch strategy employed gives priority to the effective use of renewable energy sources (PV and wind) to meet the load demand, while other sources have no predefined priorities except for the priorities determined by the power management optimization process. The excess energy from the renewable energy resources is then used to charge the energy storage devices (electrolyzer and battery) on a charge share basis. The power management optimization is integrated with sizing algorithms to minimize the overall system cost, unmet load, and fuel consumption in consideration of the unpredictable nature of the renewable energy sources (wind and PV). A differential evolution algorithm with fuzzy logic was used for the nonlinear multi objective optimization problem of the hybrid system. The design parameters of the system components and the EMS parameters (monthly charge shares of the storage device, monthly discharge shares of the hybrid generators, startup/shutdown limit of the generator, and energy storage SOCs) were obtained as the optimum solution. The result of the numerical data obtained from the calculation of the optimum monthly tilt angle of the PV panels and the optimum tower height of the wind turbine were compared with the optimal sizing result obtained at pre-defined EMSs without the developed EMS optimization algorithm. The results indicated the efficiency and capability of the proposed strategy for a hybrid power system.

\section{Energy management systems in grid-connected hybrid renewable energy systems}

In this section, we review a number of papers that analyzed grid-connected hybrid renewable energy systems. Each study strongly recommended an energy management strategy that could be used to control the flow of energy among the various energy generation and storage systems from one side of the grid to the other. The papers that analyzed renewable energy sources integrated with a smart grid are reviewed in the following section, and those suggesting a fuzzy system to perform the energy control are reviewed in a separate section. Some of the reviewed studies used linear programming to implement energy management, whereas the others used intelligent techniques for this purpose.

The following two sections include the studies that used these two approaches to implement energy management for grid-connected applications. As previously mentioned, the studies using fuzzy logic systems to implement energy management are reviewed in a separate section as many of them adopt this intelligent technique for this purpose.

\section{Energy management strategies in smart grids including renewable energy sources}

Over the last few decades, the way electricity is generated, transmitted, and consumed has changed. The need for a reliable energy source and a secure energy supply that does not depend on fossil fuels is a vital goal of most countries. Smart grids with integrated renewable energy sources fall under this goal. In smart grids, smart meters, intelligent sensors, and an instantaneous two way energy information transmission between the energy sources and the consumers should be available. This availability 


\section{www.ijtsrd.com}

enables the system to successfully manage energy delivery to consumers while allowing consumers to have their own energy consumption decisions. Although many opportunities can be achieved by smart grids, a number of challenges may arise because of the inclusion of renewable energy sources in these smart grid systems. Phuangpornpitak and Tia [17] presented some of these opportunities and a number of these challenges. The congestion in distribution networks caused by excess energy generated by renewable sources in certain instances and the intermittency in the generation in other periods are some of these challenges.

\section{Findings and discussions}

This review paper provides an intensive review of the strategies used to implement energy management in standalone hybrid renewable energy systems and gridconnected hybrid renewable systems. Special attention has been given to the energy management strategies used in smart grids.

Adopting a certain energy management strategy is essential to control the flow of energy among the various components (energy sources, storage devices, and loads) comprising the hybrid energy system. One or more than one of the following objectives can be obtained by following a certain energy management strategy:

1. Achieving a high level of system reliability and decreased percentage of occurrence of electricity interruptions.

2. Achieving high operational efficiency.

3. Reducing the cost of energy generated.

4. Increasing the lifetime of the components comprising the hybrid system.

\section{Conclusions and Recommendations}

A review of the strategies and approaches used to implement energy management both in standalone hybrid renewable energy systems and grid-connected hybrid renewable systems was conducted in this study. Special attention was given to the energy management strategies used in smart grids. Energy management strategies based on fuzzy logic systems were also addressed in detail. The application of energy management strategies in hybrid renewable energy systems is critical in achieving a high level of system reliability and operational efficiency. It has also helped in reducing the cost of energy generated and in increasing the life span of hybrid components, most especially energy storage devices (batteries). As the level of penetration of renewable energy sources increases, the need for a real-time and robust energy management approach becomes important for the hybrid connection of these energy sources together and with the energy storage devices. Therefore, further research should be conducted in this area to improve further the reliability of the entire system. Some of the features that characterize renewable energy sources are their variability and intermittency. Intermittency covers both the predictable variability and the unpredictable variations. Hybrid systems based on renewable energy sources are usually designed to consider this intermittency, and they aim to increase the reliability of these energy systems and decrease the percentage of occurrence of electricity interruptions. As these considerations are taken into account in the design, renewable sources sometimes generate more energy than the load requirement. This excess energy is usually dumped through the dump load. Developing an energy management strategy that utilizes this excess energy by directing it into certain loads, such as water heating with storage tanks, surrounding heating or air-conditioning, and pumping water, among others, is recommended.

\section{References}

[1] Perera ATD, Attalage RA, Perera KKCK, Dassanayake VPC. "Designing standalone hybrid energy systems minimizing initial investment, life cycle cost and pollutant emission". Energy 2013;54(0):220-30.

[2] Bandara K, Sweet T, Ekanayake J. "Photovoltaic applications for off-grid electrification using novel multi-level inverter technology with energy storage". Renew Energy 2011;37(1):82-8.

[3] Bansal M, Saini RP, Khatod DK. "Development of cooking sector in rural areas in India - a review". Renew Sustain Energy Rev 2013;17(0):44-53.

[4] Balcombe P, Rigby D, Azapagic A. "Motivations and barriers associated with adopting microgeneration energy technologies in the UK". Renew Sustain Energy Rev 2013;22(0):655-66. 
[5] Moghavvemi M, Ismail MS, Murali B, Yang SS, Attaran A, Moghavvemi S. "Development and optimization of a PV/diesel hybrid supply system for remote controlled commercial large scale FM transmitters". Energy Convers Manag 2013;75:542-51.

[6] Meyar-Naimi H, Vaez-Zadeh S. "Sustainable development based energy policy making frameworks, a critical review". Energy Policy 2012;43(0):351-61.

[7] Hoicka CE, Rowlands IH. "Solar and wind resource complementarity: advancing options for renewable electricity integration in Ontario, Canada”. Renew Energy 2011;36(1):97-107.

[8] Ismail MS, Moghavvemi M, Mahlia TMI. "Energy trends in Palestinian territories of West Bank and Gaza Strip: possibilities for reducing the reliance on external energy sources". Renew Sustain Energy Rev 2013;28(0):117-29.

[9] Mekhilef S, Faramarzi SZ, Saidur R, Salam Z. "The application of solar technologies for sustainable development of agricultural sector". Renew Sustain Energy Rev 2013;18(0):583-94.

[10] Rajashekara K. "Hybrid fuel-cell strategies for clean power generation". In: Proceedings of the IEEE transactions on industry applications; 2005. p. 682-9.

[11] Gupta SK, Purohit P. "Renewable energy certificate mechanism in India: a preliminary assessment". Renew Sustain Energy Rev 2013;22(0):380-92.Trans. Roy. Soc. London, vol. A247, pp. 529-551, April 1955.

[12] Beaudin M, Zareipour H, Schellenberglabe A, Rosehart W. "Energy storage for mitigating the variability of renewable electricity sources: an updated review". Energy Sustain Dev 2010;14:302-14.

[13] Strunz K, Louie H. "Cache energy control for storage: power system integration and education based on analogies derived from computer engineering". IEEE Trans Power Syst 2009;24(1):12-9.

[14] Mohod SW, Aware MV. " Energy Storage to Stabilize the Weak Wind Generating Grid". In: Power system technology and IEEE power India conference, 2008. Joint International Conference on Power con 2008, 2008.

[15] Sam Koohi-Kamali, V.V.Tyagi , N.A. Rahim, N.L.Panwar, H.Mokhlis. "Emergence of energy storage technologies as the solution for reliable operation of smart power systems: A review". Renewable and Sustainable Energy Reviews 25 (2013) 135-165 Elsevier Ltd.

[16] IEC, Grid integration of large-capacity renewable energy sources and use of large-capacity electrical energy storage, Technical report, 2013.

[17] Phuangpornpitak N, Tia S. "Opportunities and challenges of integrating renewable energy in smart grid system". Energy Procedia 2013;34(0):282-90. 